\title{
OPINION
}

\section{Did that injury happen on purpose? Does intent really matter?}

\author{
Mary D Overpeck, Elizabeth McLoughlin
}

It is sometimes hard to know our own intentions when we act-much less those of someone else. Many actions leading to injury occur in moments of distraction, high emotion, or under the influence of alcohol or other drugs. Intent to injure may be peripheral to the action. Cheng et al make a useful distinction between intending to act and intending the damage caused by the act. ${ }^{1}$

\section{Determination of intent}

Within the criminal justice system, guilt is determined by a judge and/or jury convicting a defendant of breaking a law. Within the health care system, the process is far less rigorous. For fatalities coroners and medical examiners depend upon police reports, testimony of witnesses or family members, or notes left by the deceased to code underlying cause of death. A judgment about intentionality must be made before one knows even what section of the coding system to use. This code is then appended to the death certificate, and sent to the vital statistics office. Rarely if ever is that code on the vital statistics data file revised to reflect criminal proceedings or new information. For cultural or religious reasons, suicide may be less likely to be coded in some countries than others.

When we see an injury data table with columns marked "unintentional", homicide/ assault, and suicide/self inflicted, or when the World Health Organization lists these three as essentially different "causes of death", it is tempting to think that these numbers invariably represent reality. However, research suggests otherwise, particularly for infants and young children across a number of causes of death. ${ }^{23}$ One study using information from multiple sources estimates that between $7 \%$ and $27 \%$ of fatalities of young children classified as unintentional by the medical examiner or coroner should have been classified as due to abuse and neglect, an "intentional" classification. ${ }^{3}$

Determination of intent is much more subjective for non-fatal injuries when a health care provider judges motives while taking a history of circumstances causing a patient's injury. This is particularly problematic when the child, adolescent, caretaker, or other participants are reluctant to discuss their intentions. In most non-fatal coding systems, unintentionality is assumed unless noted otherwise.

\section{What do we gain or lose by giving} primacy to intent?

Researchers in the injury field have accepted that ambiguity or incomplete coding of intent is problematic. But does coding of intent matter? Maybe the real question is: What do we gain and what do we lose by treating unintentional, assaultive, and self inflicted injury as three essentially different conditions requiring fundamentally different strategies for childhood and adolescent injury prevention?

We may gain an interest in interdisciplinary collaboration if we treat them as separable conditions. Criminal justice practitioners and some grassroots community organizations may be more interested in working together on violence prevention; mental health practitioners may be more interested in joining forces with those concerned about suicide. We may avoid some perceived political entanglements by focusing only on unintentional injury among infants, toddlers, and school age children. However, must the field be compartmentalized in order to collaborate with other fields? We think not.

We have much more to lose by compartmentalizing. We ignore new research which tells us that risk factors across all injuries have a great degree of overlap, regardless of intent. Recent reviews of risk factors for primary causes of infant injury deaths (homicide, suffocation, motor vehicle crashes, fires, and drowning) showed overlap in parental factors that were associated with increased fatalities across most causes, regardless of intent. ${ }^{4-6}$ These factors included adolescent childbearing, lack of prenatal care, low maternal education, marital status, and infant birth order.

A 1998 US National Research Council report, entitled Violence in Families: Assessing Prevention and Treatment Programs, found only one intervention for child maltreatment that was evaluated as successful. ${ }^{7}$ Interventions by nurses who visited homes of pregnant adolescents were effective in reducing both child maltreatment and unintentional injury in their young children. Subsequent follow up evaluations showed that multiple high risk behaviors, including alcohol and drug use, were reduced 
in both mothers and their children when these young children became adolescents. ${ }^{8} \mathrm{~A}$ broader understanding of parent, family, and community roles in early and evolving maladaptive behavior and conduct disorder in children may help prevent the continuous cycle of high risk children becoming high risk adolescents who become high risk parents.

\section{Avoiding compartmentalizing to strengthen prevention}

Compartmentalizing minimizes prevention research on specific mechanisms that may occur within a continuum of intent, as noted by Cheng et al. ${ }^{1}$ Compartmentalizing by intent leads us to ignore the large contributing role of alcohol and other drugs in lives of parents and adolescents, which blurs the meaning of motivation and intentionality for behavior. Caretakers, adolescents, and children may harm others out of ignorance, frustration, fatigue, or some degree of malevolence. For example, a caretaker may shake, strike, or suffocate an infant or toddler because it won't stop crying. Knowledge of household circumstances and relationship of the caretaker to the child interacting with other high risk behaviors, such as use of alcohol or drugs, may assist researchers to improve prevention techniques that address both the mechanism used to quiet the child and caretaker effectiveness. An adolescent may drive after drinking or drive beyond the limits of his or her experience to impress passengers. Prevention research on the interaction of high risk behaviors and unlimited access to cars may be more productive than determining if the youth intended to break a law by driving drunk or carelessly - or to cause injury. We rarely question intent to violate child restraint laws because research has shown that it is more important to understand both physical and behavioral impediments to restraint use. Intent is peripheral to both the act and injury mechanism for research on prevention.

Compartmentalization by intent dilutes the prevention focus on a major mechanism of child and adolescent death in the US: firearms. We know that troubled teens make suicidal gestures as a cry for help, but firearms are a more lethal mechanism of suicide than most others. Firearms are a major mechanism for suicide deaths in other countries as well. ${ }^{9}$ We know that children have shot children after finding a loaded gun in the home. Who is to blame when these tragedies occur? Blame and intent are not the real issues; the issue is the easy availability of firearms in American households. Researchers in the behavioral and political sciences would better advance prevention by exploring the role of guns in the national psyche, potential controls on availability, and how to maximize the effectiveness of existing policies.

The injury field should integrate our expertise across intent, whether it is figuring out how to make developmentally appropriate adolescent risk taking non-lethal, how to encourage people to use protective devices, how to redirect adolescents away from suicidal and/or assaultive behavior, etc. The research, policy, and programmatic agendas of the unintentional injury and violent injury communities have been converging during the past decade. All these stakeholders (public health, mental health, criminal justice) bring distinct yet complementary perspectives and expertise to preventing injury. We need more, not less, of this convergence for successful prevention.

1 Cheng TL, Wright JL, Fields CB, et al. A new paradigm of injury intentionality. Inj Prev 1999;5:59-61.

2 Christoffel KK, Zieserl E, Chiaramonte J. Should child abuse and neglect be considered when a child dies unexpectedly? Am F Dis Child 1985;139:876-80.

3 McClain PW, Sacks JJ, Froehlke RG, et al. Estimates of fatal child abuse and neglect, US, 1979-88. Pediatrics 1993;91: 338-43.

4 Brenner RA, Overpeck MD, Trumble AC, et al. Deaths due Brenner RA, Overpeck MD, Trumble AC, et al. Deaths due
to injuries in infants, United States, 1983-91. Pediatrics (in press).

5 Overpeck MD, Brenner RA, Trumble AC, et al. Risk factors for infant homicide in the United States. $N$ Engl $\mathcal{F}$ Med 1998;339:121-6.

6 Cummings P, Theis MK, Mueller BA, et al. Infant injury death in Washington state, 1981 through 1990. Arch Pediatr Adolesc Med 1994;148:1021-6.

7 Chalk R, King P, eds. Committee on the Assessment of Family Violence Interventions. Violence in families: assessing prevention and treatment programs. Washington, DC: National Academy Press, 1998.

8 Olds D, Henderson CR, Cole R, et al. Long-term effects of nurse home visitation on children's criminal and antisocial behavior. ҒAMA 1998;280:1238-44.

9 Fingerhut LA, Cox CS, Warner M, et al. International comparative analysis of injury mortality: findings from the ICE on injury statistics. Advance data from vital and health statistics. No 303. Hyattsville, MD: National Center for Health Statistics, 1998. 